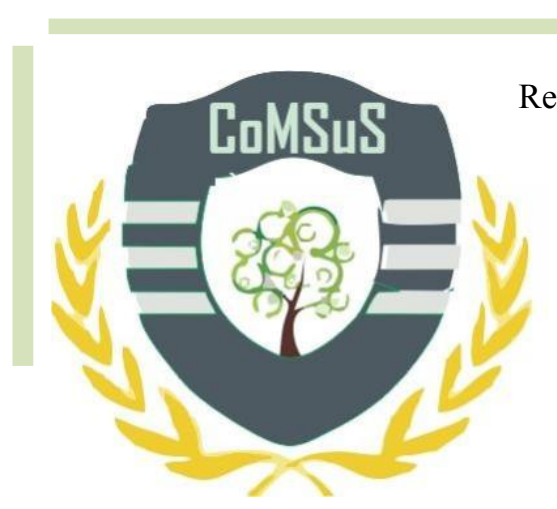

Recebido em 04/11/2017. Aprovado em 11/09/2018. Publicado em 08/11/2018.

Editor: Dr. Ivano Ribeiro

Processo de Avaliação: Double Blind Review - SEER/OJS

e-ISSN: $2359-5876$

https://doi.org/10.5935/2359-5876.20180001

\title{
GESTÃO DE PESSOAS E AS ESTRATÉGIAS DE COMPETITIVIDADE, CRESCIMENTO E SUSTENTABILIDADE DAS ORGANIZAÇÕES
}

\author{
PEOPLE MANAGEMENT AND THE COMPETITIVENESS STRATEGIES, GROWTH \\ AND SUSTAINABILITY OF ORGANIZATIONS
}

\author{
Henrique Judson Amorim Coelho ${ }^{1}$
}

\section{RESUMO}

Esse estudo pretende mostrar os resultados de uma pesquisa investigativa acerca da relação entre a área de gestão de pessoas e estratégias corporativas. O objetivo principal foi descobrir o quanto a área de gestão de pessoas é valorizada para ser incluída nas estratégias de competitividade, crescimento e sustentabilidade das organizações. Assim, foram utilizados subsídios teóricos obtidos através de pesquisa bibliográfica e uma pesquisa de campo realizada com administradores de empresas e gerentes de RH de dezoito empresas de diferentes ramos de negócios instaladas na Cidade de Pato Branco/PR e proximidades. Com base no material teórico concluiu-se que a área de gestão de pessoas deve se tornar mais estratégica e ser incluída nas estratégias corporativas; e em consequência da análise dos dados da pesquisa, foi possível concluir que a maioria das empresas ainda precisa melhorar sua visão da área de gestão de pessoas e torná-la uma área estratégica na organização.

Palavras-chave: Pessoas; Gestão de Pessoas; Estratégias; Competitividade; Crescimento; Sustentabilidade do Negócio.

\begin{abstract}
This study intends to present the results of an investigative research about the relationship between the area of people management and corporate strategies. The main purpose was to discover how much the area of people management is valued to be included in the competitiveness strategies, Growth and Sustainability of Organizations. Therefore, the study was based on theoretical subsidies obtained through bibliographic research and a field survey conducted with business managers and human resources managers of eighteen companies from different branches of business located in the city of Pato Branco - Paraná and nearby. Based on the theoretical material, it was concluded that the area of people management should become more strategic and be included in corporate strategies; and as a result of the analysis of the research data, it was possible to conclude that most companies still need to improve their view of the area of people management and make it a strategic area in the organization.
\end{abstract}

Keywords: People; People management; Strategies; Competitiveness; Growth. Business Sustainability.

\footnotetext{
${ }^{1}$ Mestrado em andamento em Administração pela Faculdade Meridional, IMED, Brasil. Especialista em Gestão Estratégica de Pessoas pela Faculdade Educacional da Lapa, FAEL, Brasil. E-mail: hjudson@msn.com
} 


\section{INTRODUÇÃO}

A gestão de pessoas é uma área que tem sido amplamente estudada nas últimas décadas. Seu alcance e influência nas organizações têm sido cada vez maiores, e vem obtendo uma crescente valorização. Entretanto, pouco se tem escrito sobre a importância que tem e os resultados que podem ser alcançados quando a gestão de pessoas é incluída nas estratégias das organizações desde sua elaboração.

É perceptível que, mesmo nos dias atuais, muitas organizações ainda mantêm a antiga e ultrapassada visão mecanicista oriunda de Taylor e Fayol onde só a cúpula da empresa deveria se envolver e conhecer as estratégias organizacionais (Knapik, 2011). Desse modo, nessas organizações, primeiro as estratégias são estabelecidas por algumas pessoas - quase sempre aquelas que compõem alta diretoria -, e depois repassadas às outras áreas da empresa, incluindo a área de gestão de pessoas. Essas áreas, então, são integradas ao processo para que se adequem às estratégias já definidas e tomem as ações necessárias para levar a organização a atingir seus objetivos. Muitas vezes, isso tem trazido resultados favoráveis, mas nem sempre para a organização com um todo. Talvez, esse processo devesse iniciar de forma diferente, incluindo desde o início áreas que podem fazer grande diferença no desenvolvimento das estratégias, logo, nos resultados; uma dessas áreas seria a área de gestão de pessoas.

Assim, pensando em como a gestão de pessoas pode ou deve influenciar nas estratégias organizacionais, o presente trabalho pretendeu, num primeiro momento, estudar sobre o grau de importância que deve ser dado à área de gestão de pessoas; depois, tentou-se descobrir, nas organizações que participaram da pesquisa de campo, quão estratégica tem sido a área de gestão de pessoas e como ela - e as pessoas -, são incluídas nas estratégias de competitividade, crescimento e sustentabilidade das organizações. Munindo-se dessas informações, pretendeuse responder à pergunta: A área de gestão de pessoas deve se envolver e participar da elaboração das estratégias de competitividade, crescimento e sustentabilidade das organizações?

\section{REFERENCIAL TEÓRICO}

A Gestão de Pessoas é, talvez, a uma das áreas corporativas sobre a qual mais se tem escrito, estudado e debatido nos últimos anos. O cenário mundial do final do século XX e início do século XXI, a globalização e a forma de trabalhar dentro das empresas, têm gerado novas demandas estratégicas e a necessidade de novas competências para a área que lida com as pessoas nas organizações, de forma que essa não seja uma área isolada e apenas operacional, mas sim estratégica e integrada a todas as outras áreas da empresa.

Nas palavras de Gil (2012, p.17), "gestão de pessoas é a função gerencial que visa a cooperação das pessoas que atuam nas organizações para o alcance dos objetivos tanto organizacionais quanto individuais". O termo 'gestão de pessoas' não é tão antigo, aparecendo por volta do final do século XX como uma evolução aos termos Administração de Pessoas e Administração de Recursos Humanos (Gil, 2012), com o objetivo de trazer uma visão mais moderna acerca das pessoas presentes nas organizações e uma maneira de gerir e lidar com as pessoas de forma mais humana e menos mecanicista, ampliando a atuação da área de RH clássica.

Nas últimas décadas, várias empresas estão compreendendo a importância dessa área e a necessidade de lhe dar a devida atenção, como afirma Chiavenato (2010, p. 11), "as organizações bem-sucedidas estão percebendo que apenas podem crescer, prosperar e manter sua continuidade se forem capazes de otimizar o retorno sobre os investimentos de todos os 
parceiros”. E a área de gestão de pessoas é responsável por alguns desses parceiros, especificamente dos parceiros internos da organização.

\title{
2.1 A gestão de pessoas e as estratégias organizacionais
}

Ser competitiva no mercado, crescer e manter sua continuidade faz parte dos objetivos de praticamente toda organização e, para alcançar esses objetivos, criam-se as estratégias que direcionam para onde se quer chegar, traçam o caminho a ser seguido e definem como seguir esse caminho de forma a manter-se na direção correta durante o processo.

Operacionalmente, todas as estratégias envolvem pessoas, pois são essas que trabalharão para que a empresa possa atingir os objetivos estabelecidos. Então a gestão de pessoas certamente estará envolvida, em maior ou menor grau, no processo. Contudo, quando se fala em Gestão de Pessoas, pensa-se em algo maior e que vai muito além de uma área operacional que usa as pessoas como recursos ou ferramentas para a organização alcançar seus objetivos unilaterais. O que se tem em mente é uma área que, quando colocada no seu devido lugar, passa a agregar valor à organização - tornando-a mais competitiva e melhor preparada para enfrentar a concorrência -, aproxima os interesses da organização e das pessoas que nela atuam - tornando o ambiente organizacional favorável ao crescimento de todos -, e fornece alguns subsídios necessários para a continuidade da organização - tornando o negócio sustentável ao longo dos anos.

Corroborando com essa visão da área de gestão de pessoas, Dante (2008) relata que as empresas estão olhando mais estrategicamente para as pessoas, percebendo seu grande potencial dentro das organizações ao afirmar que:

\begin{abstract}
Atualmente, os indivíduos são percebidos como seres humanos, dotados de personalidade própria e conhecimentos variados, como ativadores inteligentes dos recursos organizacionais, como elementos impulsionadores que dotam a organização de inteligência, talento e aprendizado, para a sua constante renovação e adaptação ao contexto, e como parceiros dela, capazes de conduzi-la à excelência e ao sucesso (Dante, 2008, p. 38).
\end{abstract}

A área de gestão de pessoas não deve ter um papel simplesmente passivo e/ou reativo dentro da organização. Ao invés disso, deve estar estratégica e ativamente integrada e interligada a todo o negócio de forma que possa ajudar a organização se tornar competitiva frente ao mercado. Morassutti (2012) elucida que a área de gestão de pessoas - "RH Estratégico" nas palavras dele -, não deve ser de gabinete, mas deve estar inserida na vida da organização:

É preciso entender como a empresa ganha dinheiro e no que é possível ajudar. Gerenciar adequadamente os ativos tangíveis e intangíveis. Concentrar-se em ações que construam um ambiente saudável, que estimule e libere o potencial das pessoas. Atuar de forma decisiva nas principais questões e mudanças estratégicas da organização. Olhar o todo e perceber que todas as partes estão interligadas. Manter a mente aberta, antecipando-se ao mundo futuro. Em resumo, estar no banco da frente. Como um copiloto eficiente e altamente confiável, que desempenha um papel extremamente importante. Tanto na gestão de pessoas quanto na estratégia dos negócios (Morassutti, 2012, p. 138).

Seguindo o processo mais comum, as estratégias elaboradas para as organizações normalmente são: a) no que diz respeito ao crescimento da organização, as estratégias envolvem ações que visam aumento dos lucros e expansão do negócio; b) com relação à competitividade, as estratégias são direcionadas para ações voltadas para marketing externo e 
melhorias/inovações do produto/serviço comercializado; e c) para a sustentabilidade do negócio, quase sempre não se tem estratégias definidas ou acredita-se que possam ser aproveitadas as ações definidas para a empresa crescer e ser competitiva.

Essas estratégias se enquadram dentro do que se espera e são necessárias para uma organização, porém, estão limitadas; um dos motivos é por não incluírem a área de gestão de pessoas. Incluem área financeira, área de marketing e área operacional, mas não a área de gestão de pessoas. Aparentemente, as pessoas continuam sendo tratadas como recursos para a organização chegar onde foi planejado. E de certa forma, a pesquisa realizada mostra uma inclinação para isso.

GRÁFICO 1: Áreas de foco estratégico

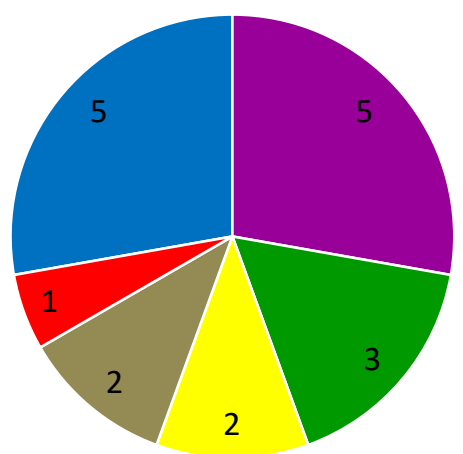

- Crescimento

- Crescimento e Sustentabilidade do Negócio

- Sustentabildade do Negócio

Competitividade e Crescimento

As três áreas no foco

- Competitividade e Sustentabilidade

Fonte: Pesquisa de campo 2017

Com base nos dados, verificou-se que dois grupos de empresas se destacaram pelas áreas comuns do foco estratégico: Grupo I - composto por cinco empresas com foco estratégico somente no crescimento; e Grupo II - composto por outras cinco empresas com foco estratégico no crescimento e sustentabilidade do negócio/empresa. Nas outras oito empresas o foco estratégico ficou distribuído de forma diversificada, conforme apresentado no Gráfico 1.

Nas empresas do Grupo I (com foco apenas no crescimento), identificou-se que o direcionamento estratégico comum às cinco empresas foi expansão comercial. Outros direcionamentos comuns a pelo menos quatro empresas do Grupo I foram: inovação de produtos e redução de custos. A Tabela 1 mostra para onde as empresas desse grupo, cujo foco está unicamente no crescimento, direcionam suas estratégias, sendo possível perceber o pouco direcionamento estratégico para questões relacionadas com a gestão de pessoas. 
TABELA 1: Subáreas de foco das Empresas do Grupo I

\begin{tabular}{|c|c|c|c|c|c|}
\hline \multirow{2}{*}{ Direcionamento estratégico } & \multicolumn{5}{|c|}{ Empresas com foco no Crescimento } \\
\hline & A & B & $\mathbf{C}$ & G & $\underline{\mathbf{R}}$ \\
\hline Expansão comercial & $\mathrm{x}$ & $\mathrm{x}$ & $\mathrm{x}$ & $\mathrm{x}$ & $\mathrm{x}$ \\
\hline Aumento do quadro de colaboradores & $\mathrm{x}$ & & & & \\
\hline Fortalecimento da marca & $\mathrm{x}$ & & & & $\mathrm{x}$ \\
\hline Melhoraria do clima organizacional & & $\mathrm{x}$ & $\mathrm{x}$ & $\mathrm{x}$ & \\
\hline Crescimento financeiro & $\mathrm{x}$ & $\mathrm{x}$ & & & $\mathrm{x}$ \\
\hline \multicolumn{6}{|l|}{ Diminuição do quadro de colaboradores } \\
\hline Inovação de produtos & & $\mathrm{x}$ & $\mathrm{x}$ & $\mathrm{x}$ & $\mathrm{x}$ \\
\hline Desenvolvimento de pessoas/equipes & & $\mathrm{x}$ & $\mathrm{x}$ & & \\
\hline \multicolumn{6}{|l|}{ Mudança/alinhamento da cultura organizacional } \\
\hline Reestruturação física & & & & $\mathrm{x}$ & $\mathrm{x}$ \\
\hline \multicolumn{6}{|l|}{ Remanejamento de colaboradores e funções } \\
\hline \multicolumn{6}{|l|}{ Desenvolvimento de programas de endomarketing } \\
\hline Redução de custos & $\mathrm{x}$ & & $\mathrm{x}$ & $\mathrm{x}$ & $\mathrm{x}$ \\
\hline \multicolumn{6}{|l|}{ Treinamento/formação de liderança } \\
\hline Aprimoramento tecnológico & $\mathrm{x}$ & $\mathrm{x}$ & & & $\mathrm{x}$ \\
\hline
\end{tabular}

Fonte: Pesquisa de campo (2017)

Lencioni $(2012$, p. 8) ressalta que ter o foco somente em estratégia, marketing, finanças e tecnologia, ou seja, áreas que envolvem o que ele chama de "qualidade de uma empresa ser inteligente", não é suficiente para que uma empresa venha a adquirir uma vantagem competitiva significativa e sustentável ao longo de um período ou fase da empresa. É necessário que o foco também seja direcionado para áreas que tornam a organização mais saudável, o que certamente envolve a área de gestão de pessoas.

No caso do Grupo II (empresas com foco no crescimento e sustentabilidade), três direcionamentos estratégicos foram comuns à cinco empresas, sendo eles: expansão comercial, melhoria do clima organizacional e treinamento/formação de liderança; outros três foram comuns a, pelo menos, quatro empresas: inovação de produtos, desenvolvimento de pessoas/equipes e redução de custos. Nesse caso, já é possível perceber que os direcionamentos estratégicos dessas empresas do Grupo II estão mais relacionados com a área de gestão de pessoas, conforme apresentado na Tabela 2. 
TABELA 2: Subáreas de foco das Empresas do Grupo II

\begin{tabular}{|l|c|c|c|c|c|}
\hline \multicolumn{1}{|c}{ Direcionamento estratégico } & \multicolumn{2}{c|}{ Empresas com foco no Crescimento e Sustentabilidade } \\
\cline { 2 - 6 } & E & L & M & N & Q \\
\hline Expansão comercial & & $\mathrm{x}$ & $\mathrm{x}$ & $\mathrm{x}$ & $\mathrm{x}$ \\
\hline Aumento do quadro de colaboradores & & $\mathrm{x}$ & & $\mathrm{x}$ & $\mathrm{x}$ \\
\hline Fortalecimento da marca & $\mathrm{x}$ & $\mathrm{x}$ & $\mathrm{x}$ & $\mathrm{x}$ & $\mathrm{x}$ \\
\hline Melhoraria do clima organizacional & $\mathrm{x}$ & & & $\mathrm{x}$ & $\mathrm{x}$ \\
\hline Crescimento financeiro & & & & \\
\hline Diminuição do quadro de colaboradores & & $\mathrm{x}$ & $\mathrm{x}$ & & $\mathrm{x}$ \\
\hline Inovação de produtos & $\mathrm{x}$ & $\mathrm{x}$ & $\mathrm{x}$ & & $\mathrm{x}$ \\
\hline Desenvolvimento de pessoas/equipes & $\mathrm{x}$ & & & $\mathrm{x}$ & $\mathrm{x}$ \\
\hline Mudança/alinhamento da cultura organizacional & $\mathrm{x}$ & & & & \\
\hline Reestruturação física & & $\mathrm{x}$ & & $\mathrm{x}$ & \\
\hline Remanejamento de colaboradores e funções & & & & $\mathrm{x}$ & $\mathrm{x}$ \\
\hline Desenvolvimento de programas de endomarketing & $\mathrm{x}$ & $\mathrm{x}$ & & $\mathrm{x}$ & $\mathrm{x}$ \\
\hline Redução de custos & $\mathrm{x}$ & $\mathrm{x}$ & $\mathrm{x}$ & $\mathrm{x}$ & $\mathrm{x}$ \\
\hline Treinamento/formação de liderança & & & & & $\mathrm{x}$ \\
\hline Aprimoramento tecnológico & & & & \\
\hline
\end{tabular}

Fonte: Pesquisa de campo (2017)

Em teoria, a tabela anterior mostra um quadro animador no que se refere à gestão de pessoas. Mesmo assim, ainda não se pode afirmar que, na prática, a área de gestão de pessoas participou da elaboração das estratégias, apesar de ser claramente perceptível que ela está envolvida nas estratégias daquelas empresas, mesmo que seja somente no desenrolar do processo. Sabe-se que não são raros os casos - conforme identificado na empresa $\mathrm{A}$ - onde o presidente ou a alta diretoria da empresa continuam a estabelecer sozinhos as estratégias corporativas, vindo depois disso o comunicado aos departamentos da empresa para que tomem ciência das estratégias e procedam com as ações necessárias. Isso coaduna, de certa forma, com a afirmação de Knapik (2011) quando a autora aborda que ainda é possível encontrar muitas organizações com visão mecanicista, onde "só a diretoria e a alta gerência devem conhecer as estratégia e metas da empresa" (Knapik, 2011, p. 39).

Dentre esses departamentos está o de Gestão de Pessoas, ou de Recursos Humanos, que entra no processo para executar o que foi planejado, tentando encontrar maneiras de engajar e motivar os funcionários na busca por alcançarem os objetivos já estabelecidos. Costa (2013, p. 16) alerta que quando o RH simplesmente recebe da diretoria as diretrizes estratégicas para implementar planos de ação, ele está agindo somente no nível tático e isso deixa de lado ações mais estratégicas que a área de gestão de pessoas poderia desempenhar.

De mono geral, parece que o tema da gestão de pessoas tem ficado tão longe das estratégias que até em um livro que trata de estratégias corporativas como "A Estratégia Segundo Drucker" de Swaim (2011), praticamente nada é falado a respeito do assunto nem sua relação com as estratégias corporativas.

Lencioni (2012), em seu livro voltado para a saúde organizacional - uma das áreas sob a responsabilidade também da Gestão de Pessoas -, afirma que a saúde organizacional oferece contexto para a estratégia, entre outras coisas. Diz ainda que a saúde organizacional é o principal fator que pode determinar o sucesso de uma organização, sendo colocado em posição superior ao talento, inteligência e inovação. Essa afirmação não é apenas teórica ou baseada em pesquisas teóricas, mas faz parte de um corpo de experiências vivenciadas por ele, como ele mesmo relata: 
Após duas décadas trabalhando com CEOs e suas equipes de altos executivos, fiquei absolutamente convencido de que a diferença fundamental entre as empresas bem-sucedidas e as que são medíocres ou fracassadas tem pouco ou nada a ver com o que elas sabem ou com a sua inteligência, mas tem tudo a ver com o quão saudáveis elas são (Lencioni, 2012, p. 9).

Morassuti (2012) comenta que o engajamento dos colaboradores não é algo fácil de se conquistar e nem acontece de uma hora para outra; mas pode ser construído no decorrer dos dias na organização através de uma relação consistente de respeito e confiança com as pessoas. Knapik (2011, p. 148) afirma que "colaboradores entusiasmados para atingir metas, encarar desafios e atender às necessidades dos clientes e fornecedores internos e externos fazem a diferença e representam uma vantagem competitiva no mundo dos negócios".

Modelos de gestão mais modernos afirmam que as organizações não devem mais tratar as pessoas como engrenagens de uma máquina maior, sendo necessário tratar as pessoas como pessoas. Quando Swaim (2011, p. 153) fala sobre mudança organizacional, ele usa uma frase do próprio Peter Drucker que diz: "As organizações que mais vão sofrer são aquelas que têm a ilusão de que amanhã será igual a ontem", e pode-se dizer o mesmo em relação à área de gestão de pessoas. Costa (2013), afirma ainda que:

Falhar na gestão da cultura organizacional, desprezar o comportamento das pessoas no trabalho, ignorar o valor da diversidade e dos conflitos de gerações, deixar de gerir o conhecimento e a aprendizagem na organização, não equilibrar recursos financeiros, sociais, e ambientais de forma sustentável podem significar a morte de organizações centenárias (Costa, 2013, p. 10-11).

Quando a área de gestão de pessoas juntamente com outras áreas estratégicas da organização criam o caminho e caminham juntas por ele, isso revela que a organização está de fato modernizada em sua amplitude e pensando em obter maior competitividade frente à concorrência, crescer de forma saudável e não unilateral, e buscando ter um negócio/empresa sustentável no presente e no futuro.

\subsection{Do RH tradicional à Gestão Estratégica de Pessoas}

Para alguns pode parecer que a mudança da nomenclatura seja apenas algo da pósmodernidade e que tanto faz usar a nomenclatura RH, Administração de RH ou Gestão de Pessoas para definir a área que cuida das pessoas em uma empresa. De fato, para empresas que têm um entendimento claro e adequado do que é e de como deve funcionar e se comportar a área de RH, a mudança de termo pode ser desnecessária, como no caso da Volvo do Brasil onde se usa RH estratégico (Morassutti, 2012). Entretanto, para muitas empresas, o RH ainda é apenas um departamento operacional responsável por cuidar dos recursos humanos da empresa. Gil (2012) ressalta que ao usar o termo recursos humanos, entende-se que a percepção das pessoas que trabalham numa organização é apenas como mais um recurso, ao lado de recursos materiais e financeiros.

Então, a primeira mudança a ser feita é no conceito que muitas empresas ainda têm a respeito da área de Recursos Humanos; depois devem ser feitas algumas mudanças na própria área. A área tradicional deve ser transformada em uma área de RH Estratégico ou área de Gestão Estratégica de Pessoas - essa última denominação parece mais adequada aos novos tempos. Não deve mais ser apenas uma área operacional que cuida de papeladas, contratações, demissões e controle do ponto dos trabalhadores. Deve se tornar uma área que se envolve estrategicamente nos diversos processos que ocorrem na organização: elaboração e criação das estratégias corporativas; recrutamento, seleção e contratação de pessoal; delineação de cargos 
e remuneração; planejamento de carreira e aposentadoria; treinamento e desenvolvimento de pessoas; formação e desenvolvimento de liderança e sucessores; avaliação de desempenho; cuidado com o clima e a saúde organizacional; entre outros. Deve ser menos operacional e mais estratégica; deixar a visão reducionista de atividades triviais alcançando uma visão mais holística e aprofundada da organização.

Alguns autores confirmam a necessidade dessa mudança e citam alguns benefícios.

"A área de Gestão de Pessoas detém muitos dos elementos requeridos para que a organização seja competitiva, já que ela permite controlar custos, melhorar os níveis de qualidade e criar distintas capacidades" (Gil, 2012. p. 40).

"Somente quando o RH está envolvido nos negócios e nas questões maiores da organização é que tem condições de criar políticas e práticas que realmente atendam às necessidades de todos os públicos. E aí poderá, de fato, cumprir o seu papel" (Morassutti, 2012. p 134).

"O RH estratégico contempla uma gestão que privilegia a mudança dos resultados finais da empresa, e por consequência, da qualidade dos talentos que dela fazem parte" (Marras, 1999 apud Costa, 2013. p. 68).

“A gestão de pessoas deve assumir seu papel estratégico nas empresas...” (Knapik, 2011. p. 193).

"Para que a área de RH possa adicionar valor à organização, servir aos seus objetivos e criar vantagens competitivas, ela precisa desempenhar papéis cada vez mais múltiplos e complexos" (Chiavenato, 2010. p. 46).

“A Gestão de Pessoas deverá desenvolver uma visão que reúna competências emocionais e visão integrada da atuação da organização, que estabeleça a comunhão de interesses entre pessoas e organização" (Menezes Junior, 2013. p. 51).

"O RH não tem outra saída: tem que ser estratégico e estar presente no negócio. Quanto a isso não há dúvidas. Mas ao mesmo tempo, não pode deixar de lado sua essência. Não pode esquecer jamais que a sua missão maior é cuidar dos recursos humanos, ou seja, de todas as questões relacionadas ao lado humano da organização" (Morassutti, 2012. p 136).

"As organizações que se posicionam de forma a inovar sua percepção de gerir pessoas têm juntado, em seu escopo geral, qualidade, desenvolvimento, lucratividade e vantagem perante outras organizações concorrentes" (Menezes Junior, 2013. p. 54).

"De acordo com Marras (2010), enquanto a gestão estratégica de pessoas interage e responde por resultados diversos, agregando valor com atitudes inovadoras no ambiente corporativo, o RH tradicional é um simples prestador de serviços, e, portanto, gerador de custos à organização" (Costa, S. N., 2013. p. 64).

As organizações modernizaram suas estruturas físicas e tecnológicas, modernizaram suas tecnologias de produção, modernizaram sua maneira de conquistar clientes e de fazer negócios, e até modernizaram alguns termos usuais e a própria maneira de falar. Porém, muitas delas não modernizaram sua maneira de lidar com as pessoas.

Tornar a área de gestão de pessoas ou o RH em uma área estratégica não favorece somente as pessoas da organização enquanto colaboradores, mas todos os parceiros. Chiavenato (2010) afirma que:

O planejamento estratégico de gestão de pessoas refere-se à maneira como a função de gestão de pessoas pode contribuir para o alcance dos objetivos organizacionais e, simultaneamente, favorecer e incentivar o alcance dos objetivos individuais dos funcionários. Trata-se de alinhar talentos e competências com as necessidades organizacionais (Chiavenato, 2010, p. 77). 
A gestão estratégica de pessoas pode se tornar um grande diferencial para qualquer empresa, pois ela influencia diretamente na vida da organização e das pessoas que lá atuam. Menezes Junior (2013, p. 54) afirma que "um ambiente organizacional permeado de ações que enaltecem o aprendizado entre pessoas, a transparência de ideias e objetivos, a humanidade e o respeito mútuo, tende a ser um ambiente fértil para o sucesso e o crescimento". Pessoas satisfeitas e motivadas, que obtêm da empresa o devido respeito e reconhecimento, levarão para suas vidas particulares muito mais que o nome da empresa.

É comum ver algumas organizações se referindo à sua área de $\mathrm{RH}$, que ainda é tradicional, como sendo um RH estratégico ou uma área de Gestão de Pessoas. Esses casos acontecem por não se ter um parâmetro para avaliar se o setor está na posição que deveria estar e se está desempenhando, de fato, a função que uma área estratégica deveria desempenhar.

Costa (2013) comenta sobre uma maneira pela qual a organização pode avaliar se realmente a área responsável pelas pessoas é uma área estratégica:

É fácil perceber se uma empresa realmente considera Recursos Humanos (RH) como uma área estratégica. Basta observar qual a posição do gestor de RH. Se o gestor de RH ocupa uma posição superior na tomada de decisões, pelo menos no mesmo nível hierárquico que a área financeira, a área de marketing e a área de operações, a empresa considera que a gestão de pessoas é estratégica. É comum encontrar empresas que dizem que "as pessoas são nosso ativo mais importante" e que o gestor de RH ocupa cargo gerencial (Gerente de RH), enquanto a empresa tem um Diretor de Comunicações, um Diretor de Operações e um Diretor Financeiro. Quando o RH é estratégico, é comum encontrar pessoas ocupando o cargo de Diretor de RH, vice-presidente de RH, Chief People Officer (CPO), dentre outras, e essa pessoa toma decisões estratégicas com o restante da diretoria (Costa, 2013, p.16).

Nos dias atuais é necessário que a alta diretoria das organizações olhe para exemplos como da Volvo do Brasil e outros pelo mundo a fora, e tome iniciativas consistentes, promovendo as mudanças necessárias nas corporações para transformar seu departamento de RH tradicional em um departamento estratégico de gestão de pessoas, seguindo a tendência mencionada por Knapik (2011) quando diz:

Hoje, com o advento da globalização, a tendência é elevar o gerenciamento de pessoas a uma dimensão mais estratégica, tendo-se uma visão mais sofisticada de administrar em parceria com as pessoas. Os colaboradores são estimulados a assumir com a direção a responsabilidade de levar a empresa a atingir seus resultados (Knapik, 2011, p. 51).

Entretanto, isso deve ocorrer não só por ser uma tendência em função da globalização, mas sim pela vontade de tornar a corporação cada vez mais competitiva, fazendo com que ela cresça além do faturamento, e para que se tenha um negócio sustentável para os próximos anos e décadas.

Fazer as mudanças necessárias no RH tradicional é um grande desafio para qualquer organização, mas esse é um caminho que pode ser trilhado nesses novos tempos. Todas as mudanças, que agora ocorrem com mais frequência do que nunca, exigem uma área de gestão de pessoas estratégica, inovadora e flexível que colabore com mais do que executar tarefas operacionais, ajudando as organizações a crescerem de forma saudável sendo mais competitivas e tornando-se sustentáveis. Ainda que poucos gostem de mudanças, ela pode ser necessária e, em alguns casos, poderá ser a única maneira de levar uma organização a um patamar mais elevado, competitivo e sustentável. 


\subsection{Incluindo a gestão de pessoas nas estratégias organizacionais}

A próxima mudança está relacionada à necessidade de incluir essa área de gestão de pessoas nas estratégias da organização, não apenas para a execução de trabalho operacional de maneira estratégica, mas desde a elaboração e criação das próprias estratégias. Essa também não é uma mudança simples, pois para alguns diretores pode dar a ideia que se está perdendo poder. Na verdade, compartilhar a elaboração das estratégias corporativas com essa área que estará diretamente relacionada àqueles que poderão fazer a coisa toda funcionar, é como se estivesse ampliando o poder. Costa (2013) diz que:

A gestão de pessoas deve passar do nível tático, cumprindo ordens oriundas da estratégia organizacional, e começar a trabalhar em colaboração na criação da estratégia. A estratégia da gestão de pessoas deve influenciar e ser influenciada pela estratégia organizacional, e não subordinada a ela (Costa, 2013, p. 11).

Incluir a gestão de pessoas na elaboração das estratégias corporativas não é dizer ao gestor responsável o que ele deve fazer com os recursos humanos disponíveis para alcançar o que foi planejado. Organizações que fizerem mais do que isso, descobrirão que estão de posse de uma ferramenta poderosa para o alcance de seus objetivos. Como disse Morassutti (2012, p. 135) "as empresas estão sentindo cada vez mais que ter um RH forte e participativo traz resultados para o negócio".

Knapik (2011, p. 53) afirma que "as pessoas podem potencializar os pontos fortes de uma empresa ou reforçar as fragilidades, dependendo de como são consideradas e gerenciadas". Se as pessoas podem potencializar os pontos fortes da empresa, então podemos dizer que é extremamente importante incluir a gestão de pessoas, ou os responsáveis por essa área, na elaboração das estratégias corporativas. Quando isso é feito, a mensagem que é transmitida para as pessoas da organização é que elas são importantes, tão importantes que pensam nelas desde o momento da elaboração das estratégias corporativas. O contrário disso é o mesmo que continuar a transmitir a ideia ultrapassada de que as pessoas são apenas recursos. Chiavenato (2012) traz luz ao que tanto se fala, mas pouco se pratica, quando escreve:

Tratar as pessoas como recursos organizacionais é um desperdício de talentos e de massa encefálica produtiva. Assim, hoje se fala em Gestão de Pessoas e não mais em recursos humanos, exatamente para proporcionar essa nova visão das pessoas - não mais como meros funcionários remunerados em função do tempo disponibilizado para a organização - mas como parceiros e colaboradores do negócio da empresa (Chiavenato, 2012, p. 34).

Passa por aí o caminho do sucesso das organizações. Infelizmente, essa não é a visão de todas as empresas, pois ainda que se ouça diretores falando que as pessoas são o ativo mais importante, a prática tem se mostrado diferente. O que tratamos nesse estudo pode revelar isso. Por exemplo: poucas empresas incluem ações voltadas ao treinamento e desenvolvimento dos colaboradores para que eles também cresçam junto com elas; poucas incluem o desenvolvimento de lideranças e de novas competências para torna-las mais competitivas; e poucas pensam no cuidado do capital humano e intelectual, tão necessário para a continuidade e sustentabilidade do negócio.

Por outro lado, temos uma experiência motivadora em solo brasileiro com a Volvo do Brasil. Morassutti (2012) deixa claro que foram as pessoas que a fizeram a empresa se tornar uma empresa de excelência ou, como eles dizem, uma empresa de classe mundial. Se referindo 
às pessoas ele disse: "Tornaram-se nosso maior diferencial competitivo ao longo dos anos, colocando-nos em posição de destaque no mundo corporativo" (Morassutti, 2012).

Isso não foi obra do acaso, mas sim fruto do que Morassutti chamou de RH Estratégico, que faz bem mais que apenas executar as tarefas operacionais, pois está "inserido nos negócios e na gestão da empresa. Com credibilidade e efetiva capacidade de agregar valor. Capaz de prover soluções que conciliem os anseios dos funcionários e os interesses da organização e dos demais públicos. Com visão de longo prazo..." (Morassutti, 2012, p. 133-134). Assim como na Volvo do Brasil, para que a gestão de pessoas esteja inserida nas estratégias de crescimento, competitividade e sustentabilidade, as empresas precisam entender o quão importante isso é e proceder com as mudanças e ajustes necessários.

Um novo modelo de gestão vem sendo experimentado por algumas organizações, onde "os profissionais de recursos humanos estão revendo seus conceitos, galgando novos espaços e participando da elaboração de planejamentos estratégicos, pois os talentos das pessoas estão sendo considerados como um diferencial estratégico e competitivo" (Knapik, 2011, p. 49).

A mudança não é tão fácil, mas de fato é o que poderá manter as empresas no mercado amanhã. Como afirma Lencioni (2012):

A transformação de uma empresa desajustada em outra saudável, além de criar uma enorme vantagem competitiva, provocará uma diferença real na vida das pessoas que lá trabalham. E para os líderes que encabeçarem tais esforços esse será um dos empreendimentos mais significativos e gratificantes que já realizaram (Lencioni, 2012, p. 14).

Organizações que pensem na sustentabilidade de seus negócios e no quando podem se tornar competitivas, deveriam considerar esse assunto, pois incluir a gestão de pessoas nas estratégias organizacionais desde quando elas são elaboradas, permitindo que os envolvidos na área de gestão de pessoas participem ativamente a partir do processo de definição das estratégias de crescimento, competitividade e sustentabilidade da empresa, poderá facilitar o caminho a ser percorrido durante a execução das estratégias e proporcionar um maior comprometimento e engajamento de todos na busca por alcançar os resultados desejados.

\section{METODOLOGIA}

A construção do presente estudo se deu através de duas pesquisas: uma pesquisa bibliográfica com o fim de descobrir a importância do assunto e a relação entre a área de gestão de pessoas e estratégias corporativas, buscando-se referencial teórico em livros relacionados e ouros materiais; e uma pesquisa de campo que foi realizada com administradores e/ou gestores de RH de 18 empresas de maior porte em cada ramo de atividade, instaladas da cidade de Pato Branco/PR e na Região Sudoeste do Paraná.

Na pesquisa de campo realizada, os administradores de empresa e gestores de $\mathrm{RH}$, escolhidos por conveniência, responderam um questionário on-line elaborado com o objetivo de analisar o foco estratégico da empresa e seus direcionamentos estratégicos e qual a relação destes com a gestão de pessoas. Para tanto, os respondentes deveriam informar, entre outras coisas, uma ou mais áreas de foco estratégico principal da empresa e depois selecionar um ou vários direcionamentos estratégicos que estivesse $(\mathrm{m})$ diretamente relacionado(s) com o foco principal; esses eram os pontos chave da pesquisa.

Todas as empresas escolhidas eram empresas locais e das proximidades, e de porte considerável no ramo em que atuam. A Tabela 3 mostra as dezoito empresas com o ramo de atuação e a quantidade média de colaboradores. 
TABELA 3: Empresas Pesquisadas

\begin{tabular}{|c|c|c|}
\hline \multirow{2}{*}{ Empresa } & Ramo de Atuação & Qtd. Colaboradores \\
\hline A & Software & de 101 a 250 \\
\hline B & Comércio de combustíveis & de 1 a 100 \\
\hline C & Jornalismo/Informação 1 a 100 \\
\hline D & Com. som e acessórios & de 1 a 100 \\
\hline E & Cooperativa & de 101 a 250 \\
\hline F & Prod. quím. para higienização 1 a 100 \\
\hline G & Hotelaria & de 1 a 100 \\
\hline H & Auto Center & de 1a 100 \\
\hline I & Varejista - venda ferramentas 1 a 100 \\
\hline J & Com. de autopeças & de 251 a 500 \\
\hline K & Instituição financeira & acima de 1000 \\
\hline L & Varejista - supermercado & de 101 a 250 \\
\hline M & Instituição financeira & de 1 a 250 \\
\hline N & Agrícola & de 251 a 500 \\
\hline O & Software & de 251 a 500 \\
\hline P & Hospitalar & \\
\hline
\end{tabular}

Fonte: Pesquisa de campo 2017

O questionário utilizado na pesquisa continha dez questões fechadas sendo as primeiras sobre o ramo de atividade da empresa e quantidade de colaboradores, seguidas por questões referentes ao foco estratégico principal e, então, as questões relacionadas ao direcionamento estratégico, na qual uma delas possuía as quinze opções relacionadas nas Tabelas 1 e 2 . O questionário foi construído com a intenção de identificar se os direcionamentos estratégicos da empresa estariam relacionados com a gestão de pessoas e se isso estaria em concordância com o foco estratégico principal. Assim, basicamente, a dimensão tratada pelo questionário versava sobre a participação da gestão de pessoas nas estratégias das empresas.

Para que as pessoas escolhidas pudessem responder o questionário, após ser feito um contato telefônico, o mesmo foi enviado por e-mail. Os dados foram analisados de forma qualitativa tendo, a priori, o objetivo de descobrir se direcionamentos estratégicos como desenvolvimento de pessoas e equipes, melhoria no clima organizacional e formação de liderança - temas que estão diretamente relacionados à gestão de pessoas -, estariam integrados no foco estratégico de crescimento, competitividade e/ou sustentabilidade das empresas. A análise também pretendia contemplar o cruzamento das informações obtidas para identificar similaridades entre as empresas que formassem grupos específicos, como por exemplo aquelas com o mesmo foco estratégico principal.

\section{ANÁLISE DOS RESULTADOS}

Com base nesse estudo, pode-se concluir que: a) a área de gestão de pessoas deve ocupar um lugar de maior relevância e mais estratégico nas organizações; e b) essa área deve se tornar uma área cada vez mais estratégica e se integrar às estratégias corporativas desde sua elaboração. Dante (2008, p. 68) falando sobre a importância dessa interrelação diz que "se atrelada à área estratégica, a área de RH se torna uma multiplicadora de relações saudáveis, do conhecimento, do comprometimento e do desempenho organizacional".

Uma organização que deseja se destacar e se manter no mercado, precisa dar liberdade para sua área de gestão de pessoas fazer a gestão com as pessoas e trabalhar estrategicamente 
para engajar todos no processo, mostrando que todos são responsáveis e obterão benefícios com o alcance dos objetivos estabelecidos nas estratégias da organização.

Chiavenato (2010) fala da adoção de novos modelos de gestão de pessoas para que a organização obtenha o sucesso desejado:

Modernamente, as organizações estão deixando de lado aspectos apenas quantitativos para focar e enfatizar aspectos qualitativos e intangíveis do capital humano necessário para conduzir a organização ao sucesso em sua estratégia organizacional. Isso significa a adoção de modelos de gestão de pessoas integrados e estrategicamente orientados (Chiavenato, 2010, p. 92).

Transformar a gestão de pessoas numa área estratégica e incluí-la no processo de criação das estratégias corporativas, pode se tornar em um grande diferencial para o sucesso da organização. É possível concluir isso pelo seguinte: a área de Gestão de Pessoas conhece e lida diretamente com as pessoas e tudo o que as envolve nas organizações; as pessoas são os ativos intangíveis que podem levar a organização a ser bem sucedida no alcance dos objetivos estabelecidos nas estratégias; o capital intelectual das organizações tem poder quase ilimitado. Assim, dar vez e voz à área de gestão de pessoas desde o processo de elaboração das estratégias até, e durante, a execução delas, criará uma sinergia entre as pessoas na busca dos objetivos e aproximará os interesses organizacionais e pessoais, o que é favorável para qualquer organização.

Em uma de suas entrevistas no programa Management TV, Jack Welch, o reconhecido CEO do século XX, demonstra a importância que ele mesmo dava à área de gestão de pessoas e às próprias pessoas. Entre outras coisas ele disse que a "gestão de pessoas era a chave do futuro da companhia". Quando fala sobre o sistema de avaliação que criou, ele conta que passava um dia em cada empresa, junto com o gestor de RH conversando com as pessoas. Ele disse:

Eu queria passar tempo com cada pessoa. Sacudi-los e ver de que eram feitos. Queria falar de seus problemas, ver como os administravam. Interessava-me mais como reagiam às coisas que em suas apresentações. É muito interessante quando pensa na questão pessoal. É a chave do negócio. Se colocar a equipe certa para trabalhar, ganha o jogo. (...) Precisa ter uma equipe enérgica, apaixonada, que saiba aonde ir, por que ir, o que há para eles. Pense: aonde vai, como chegar aí e o que há para eles. $(<$ https://www.youtube.com/watch? $\mathrm{v}=1 \mathrm{NnKpffP} 8 \mathrm{CU}>$ acessado em $15 / 06 / 2018)$.

A área de gestão de pessoas precisa estar envolvida diretamente com as estratégias da organização. E não somente os gestores da área, mas também, na medida do possível, outros colaboradores que tenham competências específicas e que possam contribuir. Dessa forma, com mais pessoas comprometidas com as estratégias da organização, possivelmente ter-se-á mais pessoas responsáveis e comprometidas também no alcance dos objetivos estabelecidos pelas estratégias. Identifica-se uma abordagem interessante em Albuquerque (2002, p. 42) ao dizer que "a participação mais ampla de colaboradores de diferentes níveis da organização na formulação estratégica é adotada também como forma de tornar esse processo mais interativo e contínuo, estimulando a comunicação, o aprendizado e o comprometimento".

Dante (2008) ao mencionar sobre a inter-relação entre a área de gestão de pessoas e a área estratégica do Grupo Gerdau diz que "a Gestão Estratégica de Pessoas está fortemente relacionada à Estratégia da organização. Essas se influenciam mutuamente, em várias dimensões" (Dante, 2008, p. 82). Certamente que para se chegar a esse ponto serão necessárias 
algumas mudanças na organização, iniciando pela alta diretoria que precisará rever seus conceitos e maneiras de lidar com a área de gestão de pessoas.

A Tabela 4 mostra a relação completa das empresas pesquisadas separadas por foco(s) estratégico(s) principal(is) juntamente com os direcionamentos estratégicos, de acordo às respostas obtidas na pesquisa.

Analisando as respostas individualmente foi possível perceber também algumas curiosidades: a Empresa I disse ter o foco somente na sustentabilidade, mas somente fortalecimento da marca e melhoria do clima organizacional fazem parte das estratégias da empresa; a Empresa A disse ter o foco somente no crescimento, mas nenhuma subárea envolvida com a gestão de pessoas faz parte das suas estratégias; a subárea onde a maior parte das empresas tem foco é a melhoria do clima organizacional - quatorze das dezoito empresas; das quatro empresas que não têm foco no crescimento, todas têm foco na sustentabilidade. Esses resultados e curiosidades apresentam possibilidades de mudanças que tendem a favorecer a organização à medida que área de gestão de pessoas se tornar mais estratégica e tiver a ingerência necessária para atuar estrategicamente dentro das empresas.

TABELA 4: Empresas participantes da pesquisa de campo 2017

\begin{tabular}{|c|c|c|c|c|c|c|c|c|c|c|c|c|c|c|c|c|c|c|c|c|}
\hline \multirow[b]{2}{*}{ Empresa } & \multirow[b]{2}{*}{ Ramo de Atividade } & \multirow[b]{2}{*}{ Qtd. Colaboradores } & \multicolumn{3}{|c|}{ Foco estratégico } & \multicolumn{15}{|c|}{ Direcionamentos estratégicos } \\
\hline & & & 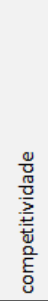 & 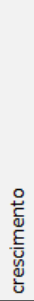 & 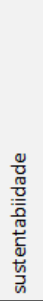 & 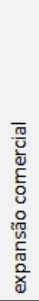 & 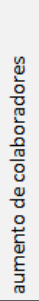 & 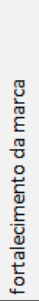 & 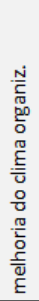 & 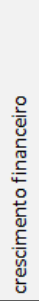 & 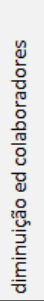 & 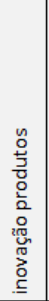 & 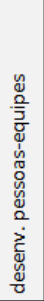 & 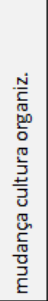 & 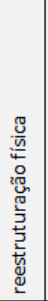 & 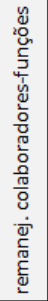 & 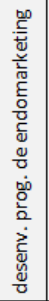 & 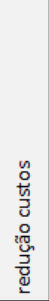 & 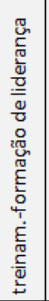 & 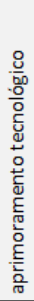 \\
\hline A & software & 101 à 250 & & $\mathrm{x}$ & & $\mathrm{x}$ & $\mathrm{x}$ & $\mathrm{x}$ & & $\mathrm{x}$ & & & & & & & & $\mathrm{x}$ & & $\mathrm{x}$ \\
\hline B & combustiveis & 1 à 100 & & $\mathrm{x}$ & & $\mathrm{x}$ & & & $\mathrm{x}$ & $\mathrm{x}$ & & $x$ & $\mathrm{x}$ & & & & & & & $\mathrm{x}$ \\
\hline $\mathrm{C}$ & jornalismo & 1 à 100 & & $\mathrm{x}$ & & $\mathrm{x}$ & & & $\mathrm{x}$ & & & $\mathrm{x}$ & $\mathrm{x}$ & & & & & $x$ & & \\
\hline G & hotelaria & 1 à 100 & & $\mathrm{x}$ & & $\mathrm{x}$ & & & $\mathrm{x}$ & & & $\mathrm{x}$ & & & $\mathrm{x}$ & & & $x$ & & \\
\hline$R$ & saúde & 1 à 100 & & $\mathrm{x}$ & & $\mathrm{x}$ & & $\mathrm{x}$ & & $\mathrm{x}$ & & $\mathrm{x}$ & & & $\mathrm{x}$ & & & $\mathrm{x}$ & & $\mathrm{x}$ \\
\hline$E$ & cooperativa & 101 à 250 & & $\mathrm{x}$ & $\mathrm{x}$ & $\mathrm{x}$ & & & $\mathrm{x}$ & $\mathrm{x}$ & & $\mathrm{x}$ & $\mathrm{x}$ & $x$ & $\mathrm{x}$ & & & $\mathrm{x}$ & $\mathrm{x}$ & \\
\hline $\mathrm{L}$ & supermercado & 101 à 250 & & $\mathrm{x}$ & $x$ & $\mathrm{x}$ & $\mathrm{x}$ & $\mathrm{x}$ & $\mathrm{x}$ & & & $\mathrm{x}$ & $\mathrm{x}$ & & & $x$ & & $\mathrm{x}$ & $\mathrm{x}$ & \\
\hline $\mathrm{M}$ & financeiro & 101 à 250 & & $\mathrm{x}$ & $\mathrm{x}$ & $\mathrm{x}$ & $x$ & & $\mathrm{x}$ & & & & $\mathrm{x}$ & & & & & & $\mathrm{x}$ & \\
\hline $\mathrm{N}$ & agrícola & 1 à 100 & & $\mathrm{x}$ & $\mathrm{x}$ & $\mathrm{x}$ & & $\mathrm{x}$ & $\mathrm{x}$ & $\mathrm{x}$ & & $\mathrm{x}$ & & $x$ & & $x$ & $\mathrm{x}$ & $x$ & $\mathrm{x}$ & \\
\hline Q & alimentício & acima de 1000 & & $\mathrm{x}$ & $x$ & $\mathrm{x}$ & & $\mathrm{x}$ & $x$ & $\mathrm{x}$ & & $\mathrm{x}$ & $x$ & $x$ & & & $\mathrm{x}$ & $x$ & $\mathrm{x}$ & $\mathrm{x}$ \\
\hline 1 & vendas ferramentas & 1 à 100 & & & $\mathrm{x}$ & & & $\mathrm{x}$ & $\mathrm{x}$ & & & & & & & & & & & \\
\hline $\mathrm{J}$ & com. autopeças & 251 à 500 & & & $\mathrm{x}$ & $\mathrm{x}$ & & & & & & & $\mathrm{x}$ & & $\mathrm{x}$ & & & & $\mathrm{x}$ & $\mathrm{x}$ \\
\hline $\mathrm{P}$ & hospitalar & 251 à 500 & & & $\mathrm{x}$ & & & & $\mathrm{x}$ & $\mathrm{x}$ & & & $\mathrm{x}$ & $\mathrm{x}$ & $\mathrm{x}$ & & & $\mathrm{x}$ & & $\mathrm{x}$ \\
\hline $\mathrm{K}$ & financeiro & acima de 1000 & $x$ & $x$ & $x$ & & & $x$ & $x$ & $x$ & & $x$ & & & & & $\mathrm{x}$ & $x$ & $\mathrm{x}$ & $x$ \\
\hline $\mathrm{H}$ & autocenter & 1 à 100 & $x$ & $x$ & $\mathrm{x}$ & & & $x$ & $\mathrm{x}$ & & & $\mathrm{x}$ & $x$ & & & & $\mathrm{x}$ & & $\mathrm{x}$ & $\mathrm{x}$ \\
\hline 0 & software & 251 à 500 & $x$ & $\mathrm{x}$ & & $\mathrm{x}$ & & $\mathrm{x}$ & $\mathrm{x}$ & $\mathrm{x}$ & & $\mathrm{x}$ & & & & & & $x$ & $\mathrm{x}$ & $x$ \\
\hline $\mathrm{F}$ & prod. quím. higieniz. & 1 à 100 & $x$ & $\mathrm{x}$ & & $\mathrm{x}$ & & $\mathrm{x}$ & & & & $\mathrm{x}$ & $x$ & & & & & & $\mathrm{x}$ & \\
\hline $\mathrm{D}$ & autocenter & 1 à 100 & $x$ & & $x$ & $\mathrm{x}$ & & $\mathrm{x}$ & $\mathrm{x}$ & $\mathrm{x}$ & & & $\mathrm{x}$ & & & & $\mathrm{x}$ & $x$ & $\mathrm{x}$ & \\
\hline
\end{tabular}

Fonte: Pesquisa de campo (2017)

Através de uma análise conjunta, somente com base no foco estratégico principal das empresas, verificou-se que na maioria das empresas o foco estratégico está no crescimento, como mostrado no Gráfico 2. Isso não é de todo prejudicial para a organização, mas pode limitar seu alcance e comprometer a sustentabilidade do negócio, principalmente se o crescimento ao qual se busca, estiver direcionado apenas para questões financeiras visando somente objetivos unilaterais da organização. 


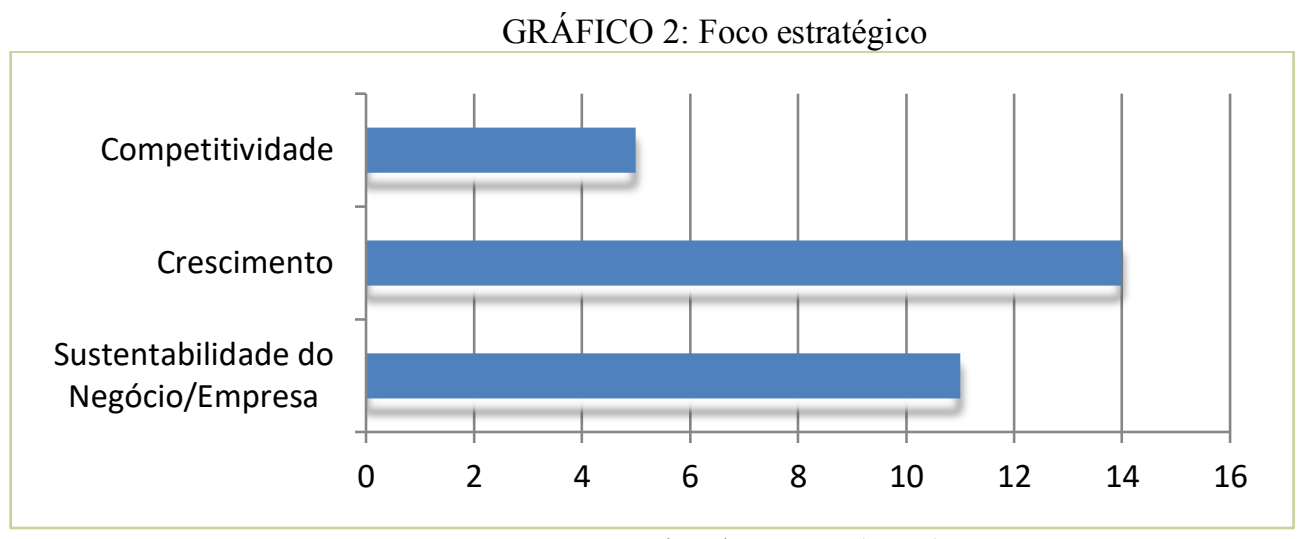

Fonte: Pesquisa de campo (2017)

Uma analogia simples pode ser feita para aclarar esse estudo, pois estabelecer estratégias corporativas sem contar com a colaboração ativa da área de gestão de pessoas e sem incluir as pessoas que estão na organização chega parecer algo incoerente. Seria como um pai de família decidir sozinho para onde toda a família vai viajar e o que farão nas férias, sem consultar ou levar em consideração características, gostos, dificuldades e anseios dos outros membros da família, e ainda esperar que as férias sejam agradáveis para todos. Isso até poderá acontecer, mas em raríssimos casos.

\section{CONCLUSÕES E CONSIDERAÇÕES FINAIS}

Com a conclusão desse artigo, identificou-se que, em se tratando de competitividade, crescimento e sustentabilidade do negócio, nada é tão vital para uma organização como uma gestão de pessoas estratégica, bem estruturada, organizada e adequada. Para isso se tornar possível, além de um estudo direcionado para os novos modelos de gestão, as organizações devem fazer algumas mudanças na área de gestão de pessoas que nelas atuam. A mudança principal deve ser incentivar e impulsionar a área de gestão de pessoas para que ela se torne uma área estratégica passando a ocupar um lugar importante nas organizações assim como as áreas de marketing e finanças, por exemplo.

A pesquisa realizada mostrou dados importantes, e uma atenção precisa ser dada ao fato da maioria das empresas ramificarem seu foco direcionando-o para uma ou duas macro áreas. $\mathrm{Na}$ verdade, as três deveriam ser pensadas em conjunto, pois para uma empresa crescer, ela deve ser e continuar sendo competitiva; para ela ser e continuar sendo competitiva, deve ter um negócio sustentável; e para ela ser sustentável, ela deve crescer de forma ordenada, estruturada e equilibrada.

Em todos os casos, a gestão de pessoas tem um papel fundamental. A premissa é que as pessoas devem ser tratadas como pessoas e por pessoas preparadas para fazer mais do que um trabalho operacional direcionado, mais do que seguir um roteiro programático de atividades e tratamentos, e mais do que buscar interesses apenas das pessoas ou apenas da organização.

No que se refere à área de gestão de pessoas, as empresas devem se preocupar com mais do que preencher vagas e ter pessoas operacionalizando processos. A gestão estratégica de pessoas pode fornecer um verdadeiro diferencial competitivo para toda organização, mas tornará isso realidade com mais facilidade quando estiver integrada às estratégias organizacionais, desde o início de sua elaboração. Talvez isso se torne mais fácil com o modelo emergente para a área de gestão de pessoas, a Consultoria Interna de $\mathrm{RH}$, mas isso poderá ser assunto de um novo trabalho. 


\section{REFERÊNCIAS}

Albuquerque, L. G. (2002). A gestão estratégica de pessoas. In: PROGEP (Org.). As pessoas na organização. (pp. 35-49). São Paulo: Gente.

Chiavenato, I. (2010). Gestão de Pessoas: O novo papel dos recursos humanos nas organizações. (3a ed). Rio de Janeiro: Elsevier.

Costa, L. V. (Org.). (2013). Gestão de Pessoas: Visão estratégica sobre temas contemporâneos. São Bernardo do Campo: Universidade Metodista de São Paulo.

Costa, S. N. Cultura organizacional: a gestão da mudança com as pessoas. In: Costa, L. V. (Org.). (2013). Gestão de Pessoas: Visão estratégica sobre temas contemporâneos. São Bernardo do Campo: Universidade Metodista de São Paulo.

Dante, G. (2008). Da seção de pessoal à gestão estratégica de pessoas: Consultoria interna de recursos humanos. Florianópolis: Editora Pandion.

Gil, A. C. (2012). Gestão de Pessoas: Enfoque nos papéis profissionais. São Paulo: Atlas.

Knapik, J. (2011). Gestão de Pessoas e Talentos. (3a ed. rev. atual. e ampl.). Curitiba: Ibepex.

Lencioni, P. (2012). A maior de todas as vantagens: a saúde organizacional como fator crítico de sucesso. Rio de Janeiro: Elsevier.

Menezes Junior, E. O. Caminhos estratégicos: modelos de gestão de pessoas. In: Costa, L. V. (Org.). (2013). Gestão de Pessoas: Visão estratégica sobre temas contemporâneos. São Bernardo do Campo: Universidade Metodista de São Paulo.

Morassutti, C. (2012). O Lado Humano do Sucesso: Como a Volvo se tornou uma empresa de classe mundial e uma das melhores do país para se trabalhar. São Paulo: Alaúde Editorial.

Swaim, R. W. (2011). A estratégia segundo Drucker: estratégias de crescimento e insights de marketing extraídos da obra de Peter Drucker/Robert Swain. Rio de Janeiro: LTC.

Welch, J. Jack Welch. <https://www.youtube.com/watch?v=1NnKpffP8CU> acessado em 04/11/2017. 